\title{
The Prognostic Value of Late Kidney Transplant Rejection Pathology Characteristics
}

\author{
Ekaterina Stolyarevich $^{1,2}$, Ludmila Artyukhina ${ }^{3}$, Elena Zakharova ${ }^{2}$, Irina Kim ${ }^{1,3}$, Ekaterina Ivanova ${ }^{1}$ and Natalia Tomilina ${ }^{1-3}$ \\ ${ }^{1}$ Federal Center of Transplantology and Artificial Organs, VI Shumakov, Moscow, Russian Federation \\ ${ }^{2}$ State University of Medicine and Dentistry, Moscow, Russian Federation \\ ${ }^{3}$ City Hospital 52, Moscow, Russian Federation
}

"Corresponding author: Elena Zakharova, Department of Nephrology Chair, State University of Medicine and Dentistry, Moscow, Russian Federation, Tel: +7 967 134 6936; Fax: +7 495945 1756; E-mail: helena.zakharova@gmail.com

Received date: May 09, 2016; Accepted date: June 22, 2016; Published date: June 29, 2016

Copyright: (c) 2016 Stolyarevich E, et al. This is an open-access article distributed under the terms of the Creative Commons Attribution License, which permits unrestricted use, distribution and reproduction in any medium, provided the original author and source are credited.

\begin{abstract}
Renal allograft rejection, represented by the wide spectrum of lesions with different pathogenesis, pathology patterns, clinical course and prognosis, still remains the most often cause of late graft dysfunction. Moreover, a combination of several factors, either of which may impact the post-transplant course, generally take place. We aimed to analyze the incidence of late renal allograft rejection variants, and to determine clinical factors and pathology features, influencing prognosis in the specific types of late renal allograft rejection.

The data obtained from 361 patients with acute $(n=227)$ or chronic $(n=134)$ late allograft rejection (mean time after kidney transplantation $48.8 \pm 46.1$ months) were analyzed retrospectively. C4d expression was found in $34 \%$ cases of acute rejection and in $58 \%$ cases of chronic rejection $64 \%$ in chronic transplant glomerulopathy and $52 \%$ in transplant vasculopathy). 5-year graft survival comprised $48 \%$ and $24 \%$ for acute and chronic transplant rejection respectively $(P<0.01)$. Combination of acute cell-mediated rejection with chronic transplant rejection did not influence significantly the prognosis for the latter.

Diffuse C4d expression on peritubular capillaries turned to be an independent prognostic factor regardless the pathology variant of renal allograft rejection. In contrast, focal C4d expression had no impact on the prognosis, which did not differ significantly from C4d-negative type. On the other hand, in acute rejection prognosis for C4dpositive forms was worse compared to C4d-negative ( $55 \%$ vs $25 \%$; $P<0.01)$, while in chronic rejection there was no difference between C4d-positive and C4d-negative forms ( $26 \%$ vs $24 \%$; $P=N S$ ). In multivariate Cox-model analysis, the following factors appeared to influence the prognosis: presence of chronic transplant glomerulopathy, features of vasculitis, severity of tubulitis, presence of thrombotic micrioangiopathy and prominence of interstitial fibrosis.
\end{abstract}

Keywords: Renal allograft rejection; Pathology; C4d expression; Prognosis

\section{Abbreviations: \\ AMR: Antibody-Mediated Rejection; C4d: C4d complement component; DSA: Donor-Specific Antibodies; PTC: Peritubular Capillaries; TCMR: T-Cell-Mediated Rejection; TG: Transplant Glomerulopathy; TVas: Transplant Vasculopathy}

\section{Introduction}

Since the advent of kidney transplantology as clinical discipline till now days, graft rejection remains the major problem, hampering the results of transplantation. Despite of invention of new potent immunosuppressive agents, which substantially diminished the rate of acute rejection (mostly early episodes), the problem is not solved so far. Moreover, recent studies demonstrate that rejection remains the leading cause of late renal allograft losses [1-3].

Depending on the dominant mechanism and the main site of injury, acute transplant rejection is subdivided into different variants: T-cellmediated rejection (TCMR) interstitial (Banff 1), TCMR vascular (intimal arteritis) (Banff 2), vascular antibody-mediated rejection (AMR) with necrotizing arteritis (Banff 3) and acute AMR with microvascular bed involvement and subsequent evolution to the chronic AMR $[4,5]$.

Despite all above mentioned variants are clearly defined according to Banff-classification, quite often a combination of several mechanisms with different types graft damage occur simultaneously or consecutively, complicating Banff scoring and hampering the diagnosis [6-8]. The sequence and interconnectivity of events through time in mixed variants of rejection, as well as the prognostic value of each particular mechanism while both cell-mediated and antibodymediated immunity become activated, are still under discussion.

Recent data demonstrated that even though pathology features of TCMR prevail, the presence of AMR substantially worsens the prognosis. It was shown that graft losses in TCMR do not exceed 4-7\%, while in the presence of antibody-mediated mechanism, defined by complement component $\mathrm{C} 4 \mathrm{~d}$ positivity $(\mathrm{C} 4 \mathrm{~d}+)$, graft losses rate expands to $30-50 \%[7,9-12]$ and vice versa, cell-mediated immunity activation, in particular resulting in vascular rejection with intimal arteritis, may worsen the prognosis for AMR $[6,8,13]$. The combination of antibody-mediated and cell-mediated vascular rejection is not that rare and some authors consider this variant as a distinct phenotype 
[14]. Moreover, molecular scores in patients with intimal arteritis may correspond both to the cell-mediated and antibody-mediated mechanisms [15].

Differential diagnostics of the renal allograft rejection is rather challenging and beyond the diversity of pathology features might be complicated by the particularities of the endothelial damage pathogenesis in AMR, which may occur in the absence of complement activation and accordingly, not accompanied by C4d expression. Indeed, the data from several studies not only confirm the existence of C4d-negative AMR, but also demonstrate its relatively high rate [16-18].

Therefore, late rejection of renal allograft is represented by the wide spectrum of different pathology patterns and their combinations, whereas the role of particular pathological and immunohistochemical characteristics for prognosis evaluation is not yet completely elucidated.

We aimed to analyze the incidence of the particular variants of late renal allograft rejection, evaluate their clinical presentation and course, and identify pathology and clinical prognostic factors for different types of late rejection.

\section{Materials and methods}

We analyzed clinical laboratory and pathology data obtained during 9-year period (2006-2014) from for 361 patients with the late $(>3$ months after transplantation) acute or chronic renal allograft rejection. The diagnosis was based on transplant biopsy findings. Mean time after transplantation constituted $48.8 \pm 46.1$ month, mean patient's age was $38.1 \pm 11.9$ y.o. In 348 (96.3\%) patients the indication for kidney allograft biopsy was graft dysfunction (mean serum creatinine level $260 \pm 160 \mu \mathrm{mol} / \mathrm{L}$ ), isolated or in combination with proteinuria (means protein excretion $1.26 \pm 1.63 \mathrm{~g} /$ day). In $13(3.6 \%)$ cases the indication for graft biopsy was isolated proteinuria $>1 \mathrm{~g} /$ day. Vast majority of renal transplant recipients received 3-drug immunosuppression regimens: cyclosporine-based (228) or tacrolimus-based (73) in combination with steroids, mycophenolates (177) or azathioprine (28), 36 patients received 2-drug regimens with cyclosporine and steroids and 24 patients at the time of biopsy were treated with the regimens using proliferative signal inhibitors.

Renal graft rejection diagnostics was performed according to Banffclassification [4]. Acute rejection variants were distinguished as follows: TCMR interstitial, TCMR vascular, AMR vascular and AMR microvascular. Chronic rejection variants were discriminated as transplant glomerulopathy (TG), transplant vasculopathy (TVas) and mixed CTR. Combinations of different chronic rejection variants with mild tubulitis, as well as with acute transplant glomerulopathy, were regarded as variants of chronic rejection.

Diagnosis of AMR (acute or chronic) was based on pathology features (microvascular inflammation or TG) along with at least one of the following symptoms: C4d positivity on peritubular capillaries (PTC) and/or presence of donor-specific antibodies (DSA). C4d staining was performed on cryo-sections by indirect immunofluorescence with FITC-conjugated anti-C4d monoclonal antibodies (Quidel Corporation, San Diego, CA). According to Banff-classification C4d staining was considered as focal if seen in $<50 \%$ of PTC or diffuse if found in $>50 \%$ of PTC.

Statistical analysis was performed using SPSS 11.5 program package. Normally distributed variables presented as the mean \pm standard deviation. Comparison between mean data performed using Student criteria. Differences significance for categorical variables was evaluated by Fisher's exact test and $\chi^{2}$ test. For abnormally distributed variables median value and interquartile range were calculated, Mann-Whitney test and Kruskall-Wallis test were used for comparison of these variables. P-value $<0.05$ was defined for statistical significance.

\section{Results}

Almost half of cases of renal allograft rejection ( $\mathrm{n}=159 ; 44 \%)$ presented with episodes of acute interstitial TCMR (including borderline changes, found in 48 patients). Vascular TCMR $(n=29 ; 8 \%)$, as well as vascular AMR with necrotizing arteritis $(n=8,2 \%)$ were found rarely. AMR with microvascular lesions (without cell-mediated component) was diagnosed in 31 patients $(8.5 \%)$. Chronic rejection was revealed more than in one third of cases $(n=134 ; 37 \%), 80$ patients out of them with chronic TG, 25 - with TVas, and 29 - with combination of chronic TG and TVas (Table 1). The combination of chronic rejection with acute interstitial $(n=24)$ or vascular $(n=14)$ TCMR was seen totally in 38 cases.

\begin{tabular}{|c|c|c|c|c|}
\hline & n (\%) & $\begin{array}{c}\text { Median time } \\
\text { after } \\
\text { transplantatio } \\
n \text { (months) }\end{array}$ & $\begin{array}{c}\text { Median } \\
\text { serum } \\
\text { creatinine } \\
(\mu \mathrm{mol} / \mathrm{L})\end{array}$ & $\begin{array}{c}\text { Median } \\
\text { proteinuria } \\
\text { (g/day) }\end{array}$ \\
\hline $\begin{array}{l}\text { Chronic transplant } \\
\text { rejection }\end{array}$ & $\begin{array}{c}134 \\
(37 \%)\end{array}$ & $\begin{array}{l}81.8(52.2 \\
126.7)^{\star *}\end{array}$ & $\begin{array}{l}220(170 ; \\
280)\end{array}$ & $\begin{array}{c}1.2(0.43 ; \\
3.3)^{\star *}\end{array}$ \\
\hline $\begin{array}{l}\text { Chronic transplant } \\
\text { glomerulopathy }\end{array}$ & $\begin{array}{c}80 \\
(22 \%)\end{array}$ & $\begin{array}{l}74.6(40.3 \\
112.2)\end{array}$ & $\begin{array}{l}210(170 \\
270)\end{array}$ & $\begin{array}{l}1.2(0.65 ; \\
3.3)\end{array}$ \\
\hline $\begin{array}{l}\text { Transplant } \\
\text { vasculopathy }\end{array}$ & $25(7 \%)$ & $\begin{array}{l}45.5(13.9 \\
91.8)\end{array}$ & $\begin{array}{l}250(180 \\
390)\end{array}$ & $\begin{array}{l}0.32(0.2 \\
1.4)\end{array}$ \\
\hline Mixed & $29(8 \%)$ & $\begin{array}{c}105.8(79.5 \\
162.5)\end{array}$ & $\begin{array}{l}220(180 ; \\
300)\end{array}$ & $\begin{array}{l}2.0(1.4 \\
3.5)\end{array}$ \\
\hline $\begin{array}{l}\text { Acute transplant } \\
\text { rejection }\end{array}$ & $\begin{array}{l}227 \\
(63 \%)\end{array}$ & $16.8(6.1 ; 45.9)$ & $\begin{array}{l}250(180 ; \\
310)\end{array}$ & $\begin{array}{c}0.4(0.1 \\
1.0)\end{array}$ \\
\hline Borderline changes & $\begin{array}{c}48 \\
(13 \%)\end{array}$ & $10(4.5 ; 25.2)^{\star}$ & $\begin{array}{l}170(150 \\
250)\end{array}$ & $\begin{array}{l}0.45(0.1 \\
1.0)\end{array}$ \\
\hline Banff 1 & $\begin{array}{c}111 \\
(31 \%)\end{array}$ & $22.3(8.3 ; 55.3)$ & $\begin{array}{l}230(180 \\
300)\end{array}$ & $\begin{array}{l}0.32(0.12 \\
\quad 0.72)\end{array}$ \\
\hline Banff 2 & $29(8 \%)$ & $17.5(6.6 ; 58.7)$ & $\begin{array}{l}260(180 ; \\
370)\end{array}$ & $\begin{array}{c}0.53(0.17 \\
1.9)\end{array}$ \\
\hline Banff 3 & $8(2 \%)$ & $17.7(9.0 ; 59.4)$ & $\begin{array}{l}580(420 \\
700)^{*}\end{array}$ & $\begin{array}{l}0.35(0.1 \\
0.9)\end{array}$ \\
\hline $\begin{array}{l}\text { Antibody-mediated } \\
\text { microvascular }\end{array}$ & $31(9 \%)$ & $\begin{array}{l}41.1(15.3 \\
81.5)\end{array}$ & $\begin{array}{l}210(170 \\
310)\end{array}$ & $\begin{array}{c}0.55(0.17 \\
1.4)\end{array}$ \\
\hline
\end{tabular}

Table 1: Clinical and laboratory characteristics of different variants of late renal allograft rejection.

Time after transplantation and clinical presentation significantly differ between the variants of graft rejection: thus chronic rejection occurred substantially later comparing to acute ( 81.8 vs 16.8 months) and presented with markedly higher proteinuria ( $1.2 \mathrm{vs} 0.4 \mathrm{~g} /$ day). However serum creatinine level did not differ between these two groups ( 220 vs $250 \mu \mathrm{mol} / \mathrm{L}$ ). Alongside that renal allograft dysfunction varied significantly in different types of acute rejection and was most severe in vascular AMR, while time after transplantation and level of 
Citation: Stolyarevich E, Artyukhina L, Zakharova E, Kim I, Ivanova E, et al. (2016) The Prognostic Value of Late Kidney Transplant Rejection

proteinuria did not show significant differences between acute rejection variants (Table 1 ).

Renal allograft survival (Table 2) was associated with pathology variant of rejection, being significantly higher in patients with acute compared to chronic rejection: 5 -year graft survival was $48 \%$ and $24 \%$ respectively $(\mathrm{P}<0.001)$. With this the presence of acute rejection features on top of chronic changes did not significantly influence the prognosis, 5-year survival turned to be $24 \%$ and $13 \%$ for "pure" chronic rejection and the combination of chronic and acute rejection respectively (Figure 1A). Within the acute rejection itself the prognosis depended on the pathology pattern and was most favorable in TCMR interstitial variant, and the worst in AMR vascular variant (Figure 1B). Among patients with chronic rejection graft survival was the highest in isolated TV as compared to TG, isolated or in combination with TV as $(\mathrm{P}<0.05)$ (Figure 1C).

\begin{tabular}{|l|c|c|c|}
\hline & 1-year & 2-years & 5-years \\
\hline Borderline changes & $96 \%$ & $94 \%$ & $76 \%$ \\
\hline Banff 1 a-b & $79 \%$ & $69 \%$ & $43 \%$ \\
\hline Banff 2 a-b & $65 \%$ & $53 \%$ & $36 \%$ \\
\hline Banff 3 & $25 \%$ & $13 \%$ & $13 \%$ \\
\hline Micro-vascular & $83 \%$ & $67 \%$ & $42 \%$ \\
\hline Chronic transplant glomerolopathy & $70 \%$ & $40 \%$ & $12 \%$ \\
\hline Chronic transplant vasculopathy & $73 \%$ & $68 \%$ & $51 \%$ \\
\hline Chronic transplant glomerulopathy + vasculopathy & $50 \%$ & $22 \%$ & $18 \%$ \\
\hline
\end{tabular}

Table 2: Renal allograft survival depending on the variant of rejection.

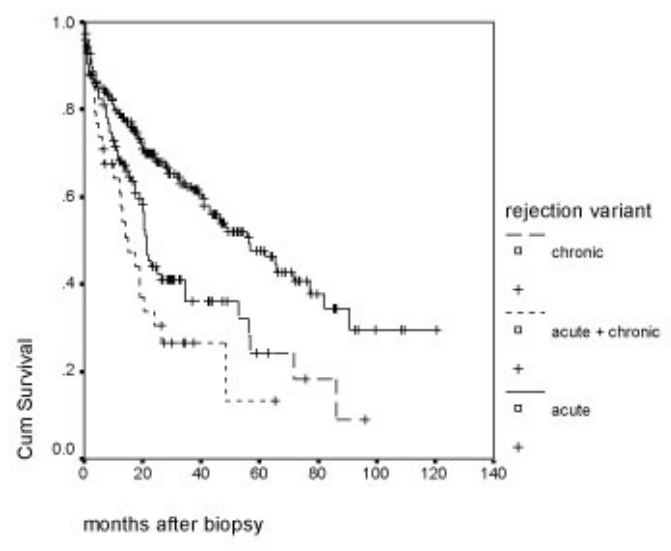

Figure 1A: Renal allograft survival depending on acute or chronic rejection.

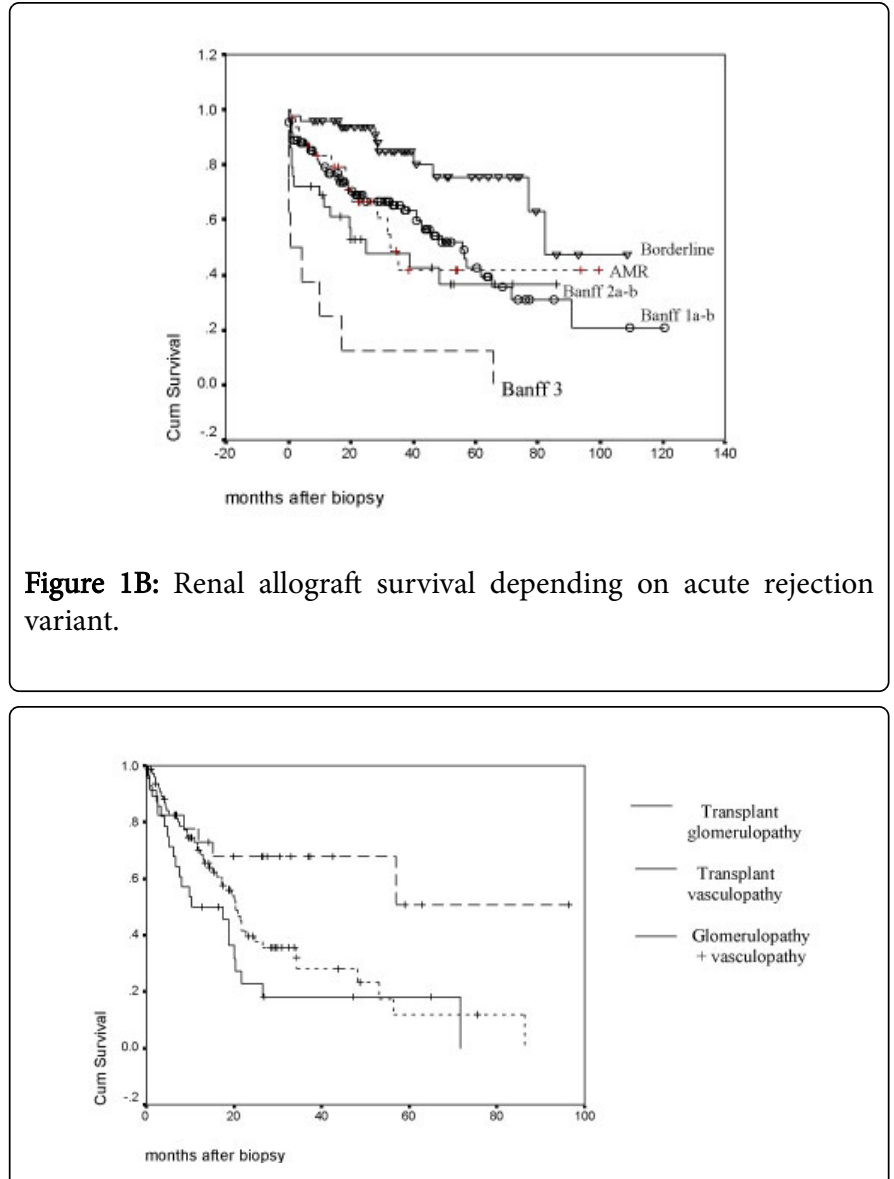

Figure 1C: Renal allograft survival depending on chronic rejection variant.

Activation of antibody-mediated immunity was found to some extent in all variants of rejection (excluding borderline changes - the latter in presence of C4d expression were always combined with the features of microvascular lesions and were considered as one or another variant of AMR) - its proportion comprised 34\% of cases in acute rejection and $58 \%$ in chronic rejection, whereupon the rate of occurrence and type of expression (diffuse or focal) differed depending on pathology pattern (Figure 2).

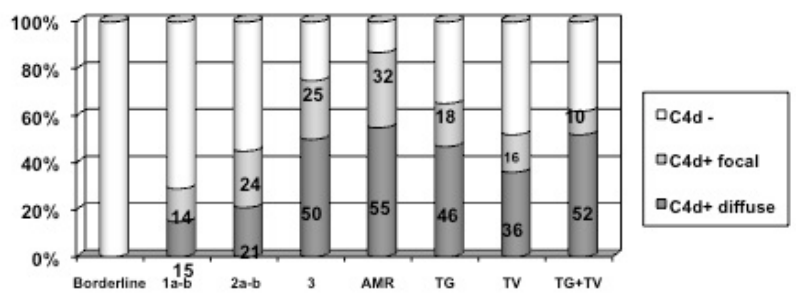

Figure 2: C4d-positivity rate in different rejection variants. 
Citation: Stolyarevich E, Artyukhina L, Zakharova E, Kim I, Ivanova E, et al. (2016) The Prognostic Value of Late Kidney Transplant Rejection

Page 4 of 6

Therefore, acute rejection developed predominantly as TCMR in $63 \%$ of cases, mixed (TCMR + AMR) variant took place in $20 \%$ of patients and in $17 \%$ of cases AMR without cell-mediated component (microvascular in $14 \%$ and vascular/Banff 3 - in $3 \%$ ) was diagnosed. C4d staining on PTC was found in $60 \%$ of CTR cases.

PTC C4d-positivity had independent prognostic value, influencing the course of renal graft rejection regardless of its pathology variant (Figure 3). With that unfavorable impact of C4d-positivity was noticed only for diffuse expression, while in cases with focal expression prognosis did not differ from C4d-negative patients.

\begin{tabular}{|l|c|c|c|c|}
\hline \multirow{2}{*}{ Banff score } & P-value & OR & \multicolumn{2}{|c|}{$95.0 \%$ Cl for OR } \\
\hline$T$ & & & Lower & Upper \\
\hline V & .000 & 1.431 & 1.188 & 1.395 \\
\hline G & .000 & 1.572 & 1.242 & 1.989 \\
\hline CG & .267 & 1.132 & .909 & 1.411 \\
\hline CV & .000 & 1.846 & 1.434 & 2.376 \\
\hline CI & .419 & .946 & .827 & 1.082 \\
\hline GS & .000 & 1.021 & 1.012 & 1.031 \\
\hline AH & .137 & 1.006 & .998 & 1.013 \\
\hline PTC & .773 & .978 & .839 & 1.139 \\
\hline TMA & .014 & .977 & .791 & 1.209 \\
\hline C4d & .065 & 1.175 & 0.990 & 1.395 \\
\hline
\end{tabular}

Table 3: Multivariate Cox-regression model for the renal allogtraft losses.

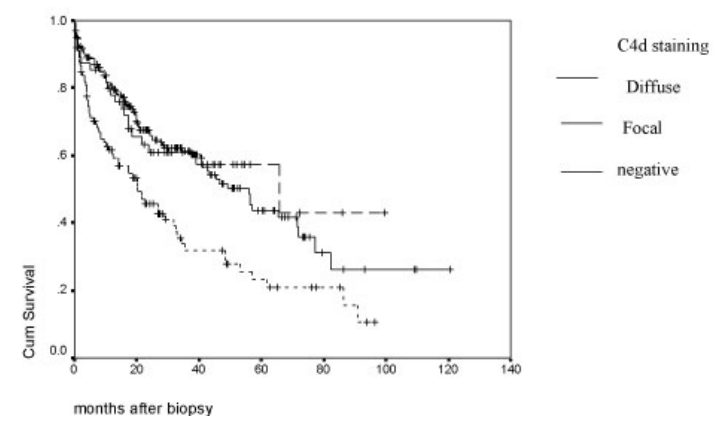

Figure 3: Renal allograft survival depending on C4d expression.

However, performing more detailed analysis we found, that worsening of prognosis in C4d-positive rejection was characteristic only for acute variants with 5 -year graft survival $25 \%$ and $55 \%$ for C4dpositive and C4d-negative respectively $\mathrm{P}<0.001$ (Figure 4A), while in chronic rejection 5-year graft survival did not differ between C4dpositive and C4d-negative cases (26\% vs $24 \%$; P - NS) (Figure 4B).

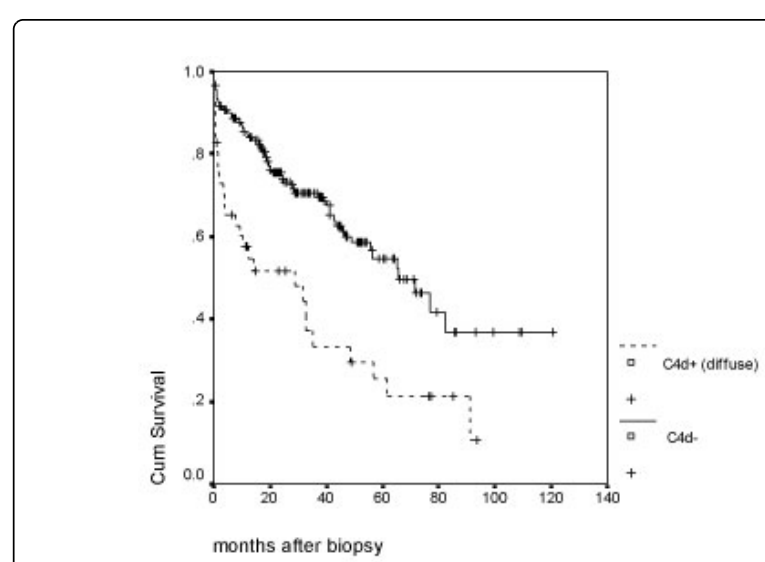

Figure 4A: Renal allograft survival in acute rejection depending on PTC C4d ${ }^{*}$ expression ( ${ }^{*}$ Diffuse expression only).

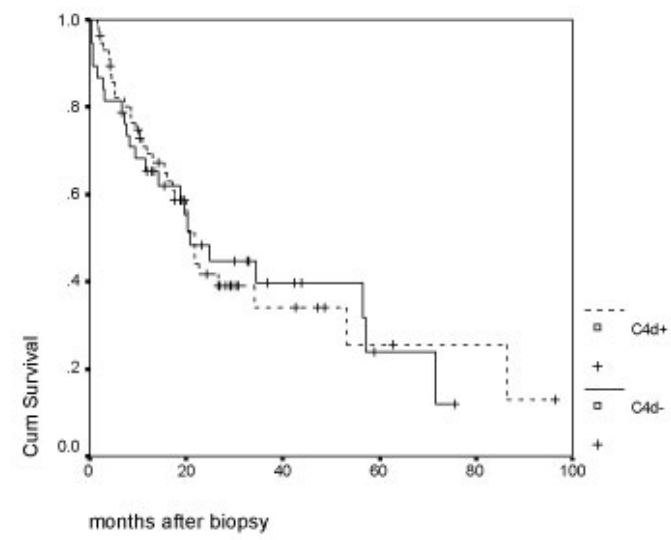

Figure 4B: Renal allograft survival in chronic rejection depending on PTC C4 ${ }^{*}$ expression ( ${ }^{*}$ Diffuse expression only).

In multivariate Cox-model analysis (Table 3) the negative prognostic factors turned to be chronic TG, which enhanced the probability of the graft loss up to $70 \%$, signs of vasculitis and its severity, severity of tubulitis, presence of thrombotic microangiopathy, and also the extent of interstitial fibrosis (relative risk for the graft loss increased at $20 \%$ with increase of interstitial fibrosis at each $10 \%$ ).

\section{Discussion}

Renal allograft damage associated with immune response activation includes broad variety of lesions with different pathogenesis, pathology, clinical course and prognosis. In addition, combinations of several factors, either of which may independently impact the course of renal allograft damage in fact take place, particularly late after transplantation. The role of these factors is still under discussion.

The most important graft rejection feature, reflecting its mechanism and defining the course and long-term prognosis, is C4d expression on PTC. The prognostic value of this hallmark is confirmed for early rejection episodes $[10,11]$ however it is not generally accepted as a negative prognostic factor in the late acute and chronic transplant rejection. Even though several studies showed that renal graft survival 
in C4d-positive late AMR was significantly lower compared to C4dnegative cases [19-22], other authors did not confirm this association [23-25]. Keiran et al., who studied the renal graft biopsies performed late ( $>10$ years) after transplantation, demonstrated prognostic value of C4d expression only in its association with TG, while in the absence of the latter C4d-positivity did not influence the prognosis [26]. Possible explanation for this controversy might be assumption of the diversity of late AMR variants, including growing number of its C4d-negative forms.

Thereby findings concerning focal C4d expression become increasingly important. Given that Banff-classification consider only diffuse expression as diagnostic criteria, the data from several studies, indicating that focal C4d expression was associated with worsening of graft survival, cannot be neglected, although decrease of survival was less prominent compared to such in cases of diffuse C4d-positivity. That is in particular characteristic for the late rejection episodes in which focal C4d expression is seen more often, probably reflecting lower activity of AMR, but correlating, however, with the presence of DSA, features of microvascular inflammation and TG [27-29].

Our data also favor the independent influence of $\mathrm{C} 4 \mathrm{~d}$ expression on PTC on the late ATR prognosis. Despite the fact that in the vast majority of C4d-positive rejection cases the mechanism of the lesions was combined (TCMR + AMR), diffuse C4d expression on PTC however affected the prognosis regardless of pathology pattern, while the prognostic value of focal C4d+ was quite limited.

Along with C4d expression, another important criteria for AMR is capillaritis with neutrophil and monocyte fixation within glomerular and peritubular capillaries. These pathology features mainly correlate with the presence of DSA and C4d-positive staining on PTC and further lead to the evolution towards chronic TG and decrease of the graft function. On the other hand, in some cases such changes may be revealed isolated or preclude the appearance of other signs of AMR, nevertheless influencing the course and prognosis of the graft nephropathy $[16,30]$. Notably, the study performed by Loupy et al. showed the 4-times increased risk of CTR in presence of microvascular inflammation and DSA-positivity, independently from C4d expression on PTC [28]. Similar findings come from the study of Miura et al. [30] all patients, who, according to the protocol biopsies, demonstrated the features of sub-clinical microvascular inflammation after the desensitization, later developed chronic TG. Importantly, DSA were found only in $60 \%$ and C4d expression - just in $20 \%$ of cases [31]. In the study performed by Sis et al. possible existence of C4d-negative AMR was confirmed by the expression of 12 endothelium-associated genes in DSA-positive patients with microvascular inflammation, which was not always accompanied by C4d expression on PTC [32].

The role of complement activation in chronic rejection is widely discussed over last years. Despite obvious involvement of antibodymediated immunity in chronic rejection, the data concerning prevalence of C4d expression in chronic TG vary in the wide range from $25 \%$ [33] to $66 \%$ [34], comprising $53 \%$ as a mean [35]. Interestingly, even in the cases of C4d-negative TG, the role of DSA in its pathogenesis is clearly defined: thus in the study performed by Gloor et al. DSA were found in $82 \%$ of patients with TG, while C4d expression - only in $25 \%$ of cases [33]. That might be explained by the different sensitivity of $\mathrm{C} 4 \mathrm{~d}$ detection methods and also by the dynamic nature of the rejection, in which course C4d expression may appear and disappear over the time depending on the activity of the process. Beyond that, there are some findings confirming the enhancing role of other mechanisms of DSA-driven endothelial damage in late chronic rejection, which are not directly associated with complement activation $[36,37]$. However in general the literature data concerning this issue are controversial - while some authors describe important influence of C4d-positivity on chronic rejection prognosis [26,38], the others indicate that prognosis for $\mathrm{C} 4 \mathrm{~d}$-posistive chronic rejection does not differ from such for C4d-negative or even is better [17,39].

Our data, demonstrating lack of prognostic value of C4d expression for chronic rejection, most probably bear evidence that C4d-expression in chronic rejection reflects just the phase of the dynamic process at the time of biopsy (which in fact is a snap-shot rather that a movie). In the other words we do not regard C4d-positive chronic rejection as a specific form. Of note, the rate of C4d-positive forms did not differ between the variants of chronic rejection, which favors the hypothesis of the role of antibody-mediated immunity also in the TV as pathogenesis.

Pathology pattern of TG is also regarded as independent prognostic factor, which is not associated with concomitant features of rejection. That was confirmed by the data from the protocol [40], as well as indicated biopsies [33]. Our study also confirms negative influence of this factor on the rejection prognosis - in Cox-regression model TG demonstrated the highest negative prognostic value compared to other pathology characteristics. In contrast, the presence of acute TCMR on the top of already existing chronic rejection did not show additional negative impact for the prognosis in general.

\section{References}

1. Gaston RS, Cecka JM, Kasiske BL, Fieberg AM, Leduc R, et al. (2010) Evidence for antibody-mediated injury as a major determinant of late kidney allograft failure. Transplantation 90: 68-74.

2. Gourishankar S, Leduc R, Connett J, Cecka JM, Cosio F, et al. (2010) Pathological and clinical characterization of the "troubled transplant": data from the DeKAF study. Am J Transplant 10: 324-330.

3. El-Zoghby ZM, Stegall MD, Lager DJ, Kremers WK, Amer H, et al. (2009) Identifying Specific Causes of Kidney Allograft Loss. Am J Transplant 9: 527-535.

4. Sis B, Mengel M, Haas M, Colvin RB, Halloran PF, et al. (2010) Banff '09 Meeting Report: Antibody Mediated Graft Deterioration and Implementation of Banff Working Groups. Am J Transplant 10: 464-471.

5. Nickeleit V, Andreoni K (2007) The classification and treatment of antibody-mediated renal allograft injury: Where do we stand? Kidney Int 71: 7-11.

6. Matignon M, Muthukumar V, Seshan SV, Suthanthiran M, Hartono C, et al. (2012) Concurrent Acute Cellular Rejection Is An Independent Risk Factor For Renal Allograft Failure In Patients With C4d Positive Antibody-Mediated Rejection. Transplantation 94: 603-611.

7. Willicombe M, Roufosse C, Brookes P, McLean AG, Galliford J, et al. (2014) Acute Cellular Rejection: Impact of Donor-Specific Antibodies and C4d. Transplantation 97: 433-439.

8. Randhawa P (2015) T-cell-mediated rejection of the kidney in the era of donor-specific antibodies: diagnostic challenges and clinical significance. Curr Opin Organ Transplant 20: 325-332.

9. Halloran PF, Chang J, Famulski K, Hidalgo LG, Salazar ID, et al. (2015) Disappearance of $\mathrm{T}$ Cell-Mediated Rejection Despite Continued Antibody-Mediated Rejection in Late Kidney Transplant Recipients. J Am Soc Nephrol 26: 1711-1720.

10. Herzenberg AM, Gill JS, Djurdjev O, Magil AB (2002) C4d deposition in acute rejection: An independent long-term prognostic factor. J Am Soc Nephrol 13: 234-241.

11. Regele H, Exner M, Watschinger B, Wenter C, Wahrmann M, et al. (2001) Endothelial C4d deposition is associated with inferior kidney allograft outcome independently of cellular rejection. Nephrol Dial Transplant 16: 2058-2066. 
Citation: Stolyarevich E, Artyukhina L, Zakharova E, Kim I, Ivanova E, et al. (2016) The Prognostic Value of Late Kidney Transplant Rejection Pathology Characteristics. J Transplant Technol Res 6: 165. doi:10.4172/2161-0991.1000165

Page 6 of 6

12. Wang R, Wang H, Chen J, Wu J, Wang Y, et al. (2009) C4d deposition in allograft renal biopsies is an independent risk factor for graft failure. Nephrology 14: 527-532.

13. Lefaucheur C, Nochy D, Hill GS, Suberbielle-Boissel C, Antoine C, et al. (2007) Determinants of Poor Graft Outcome in Patients with AntibodyMediated Acute Rejection. Am J Transplant 7: 832-841.

14. Lefaucheur C, Loupy A, Vernerey D, Duong-Van-Huyen JP, Suberbielle C, et al. (2013) Antibody-mediated vascular rejection of kidney allografts: a population-based study. Lancet 381: 313-319.

15. Salazar ID, Merino López M, Chang J, Halloran PF (2015) Reassessing the Significance of Intimal Arteritis in Kidney Transplant Biopsy Specimens. J Am Soc Nephrol 26: 3190-3198.

16. Haas M (2011) C4d-negative antibody-mediated rejection in renal allografts: evidence for its existence and effect on graft survival. Clin Nephrol 75: 271-278.

17. Sis B, Campbell PM, Mueller T, Hunter C, Cockfield SM, et al. (2007) Transplant glomerulopathy, late antibody-mediated rejection and the ABCD tetrad in kidney allograft biopsies for cause. Am J Transplant 7: 1743-1752.

18. Djamali A, Kaufman DB, Ellis TM, Zhong W, Matas A, et al. (2014) Diagnosis and Management of Antibody-Mediated Rejection: Current Status and Novel Approaches. Am J Transplant 14: 255-271.

19. Ciszek M, Ptasińska AP, Durlik M, Paczek L (2006) C4d-positive renal transplants: single-center clinical outcomes. Clin Transpl 2006: 405-412.

20. Kedainis RL, Koch MJ, Brennan DC, Liapis H (2009) Focal C4d + in Renal Allografts is Associated with the Presence of Donor Specific Antibodies and Decreased Allograft Survival. Am J Transplant 9: 812-819.

21. Pefaur J, Diaz P, Panace R, Salinas P, Fiabane A, et al. (2008) Early and late humoral rejection: a clinicopathologic entity in two times. Transplant Proc 9: 3229-3236.

22. Poduval RD, Kadambi PV, Josephson MA, Cohn RA, Harland RC, et al. (2005) Implications of immunohistochemical detection of C4d along peritubular capillaries in late acute renal allograft rejection. Transplantation 79: 228-235.

23. Mengel M, Bogers J, Bosmans JL, Seron D, Moreso F, et al. (2005) Incidence of C4d stain in protocol biopsies from renal allografts: results from a multicenter trial. Am J Transplant 5: 1050-1056

24. Nickeleit V, Zeiler M, Gudat F, Thiel G, Mihatsch MJ, et al. (2002) Detection of the complement degradation product C4d in renal allografts: diagnostic and therapeutic implications. J Am Soc Nephrol 13: 242-251.

25. Satoskar AA, Lehman AM, Nadasdy GM, Sedmak DD, Pesavento TE, et al. (2008) Peritubular capillary C4d staining in late acute renal allograft rejection--is it relevant? Clin Transplant 22: 61-67.

26. Kieran N, Wang X, Perkins J, Davis C, Kendrick E, et al. (2009) Combination of Peritubular C4d and Transplant Glomerulopathy Predicts Late Renal Allograft Failure. J Am Soc Nephrol 20: 2260-2268.

27. Loupy A, Hill GS, Suberbielle C, Charron D, Anglicheau D, et al. (2011) Significance of C4d Banff Scores in Early Protocol Biopsies of Kidney
Transplant Recipients with Preformed Donor-Specific Antibodies (DSA). Am J Transplant 11: 56-65.

28. Magil AB, Tinckam KJ (2006) Focal peritubular capillary C4d deposition in acute rejection. Nephrol Dial Transplant 21: 1382-1388.

29. Haas M (2012) Pathologic features of antibody-mediated rejection in renal allografts: an expanding spectrum. Curr Opin Nephrol Hypertens 21: 264-271.

30. Miura M, Harada H, Fukasawa Y, Hotta K, Itoh Y, et al. (2012) Long-term histopathology of allografts in sensitized kidney recipients. Clin Transplant Suppl 24: 32-36.

31. Sis B, Jhangri GS, Bunnag S, Allanach K, Kaplan B, et al. (2009) Endothelial gene expression in kidney transplants with alloantibody indicates Antibody-mediated damage despite lack of C4d staining. Am J Transplant 9: 2312-2323.

32. Gloor JM, Sethi S, Stegall MD, Park WD, Moore SB, et al. (2007) Transplant Glomerulopathy: Subclinical Incidence and Association with Alloantibody. Am J Transplant 7: 2124-2132.

33. Vongwiwatana A, Gourishankar S, Campbell PM, Solez K, Halloran PF, et al. (2004) Peritubular capillary changes and C4d deposits are associated with transplant glomerulopathy but not IgA nephropathy. Am J Transplant 4: 124-129.

34. Regele H, Bohmig GA, Habicht A, Gollowitzer D, Schillinger M, et al. (2002) Capillary deposition of complement split product C4d in renal allografts is associated with basement membrane injury in peritubular and glomerular capillaries: A contribution of humoral immunity to chronic allograft rejection. J Am Soc Nephrol 13: 2371-2380.

35. Hidalgo LG, Sis B, Sellares J, Campbell PM, Mengel M, et al. (2010) NK cell transcripts and NK cells in kidney biopsies from patients with donorspecific antibodies: evidence for NK cell involvement in antibodymediated rejection. Am J Transplant 10: 1812-1822.

36. Plissonier D, Henaff M, Poncet P, Paris E, Tron F, et al. (2000) Involvement of antibody-dependent apoptosis in graft rejection. Transplantation 69: 2601-2608.

37. David-Neto E, Prado E, Beutel A, Ventura CG, Siqueira SA, et al. (2007) C4d-positive chronic rejection: A frequent entity with a poor outcome. Transplantation 84: 1391-1398.

38. Mauiyyedi S, Pelle PD, Saidman S, Collins AB, Pascual M, et al. (2001) Chronic humoral rejection: identification of antibody-mediated chronic renal allograft rejection by $\mathrm{C} 4 \mathrm{~d}$ deposition in peritubular capillaries. J Am Soc Nephrol 12: 574-582.

39. Cosio FG, Grande JP, Wadei H, Larson TS, Griffin MD, et al. (2005) Predicting subsequent decline in kidney allograft function from early surveillance biopsies. Am J Transplant 5: 2464-2472.

40. Suri DL, Tomlanovich SJ, Olson JL, Meyer TW (2000) Transplant glomerulopathy as a cause of late graft loss. Am J Kidney Dis 35: 674-680. 